\title{
Aislamiento de Clostridium tetani en la ciudad de Puntarenas, Costa Rica y el fenómeno de "swarming".
}

\section{Artículo Original}

Francisco Hernández-Chavarría ${ }^{1,3}$, Fernando Cháves ${ }^{2}$, Maricela Umaña ${ }^{1}$.

${ }^{1}$ Laboratorio de Investigación en Bacteriología Anaerobia (LIBA), Facultad de Microbiología, Instituto Clodomiro Picado, ${ }^{3}$ Unidad de Microscopia Electrónica, San José, Costa Rica.

\section{RESUMEN.}

Objetivo. Determinar la ocurrencia de Clostridium tetani a partir de muestras de suelo colectadas en la ciudad de Puntarenas, Costa Rica, y evaluar su toxigenicidad usando una prueba de ELISA de captura.

Material y métodos. Treinta muestras de suelo fueron colectadas y secadas a $35^{\circ} \mathrm{C}$ durante al menos dos semanas. De cada muestra se hizo una suspensión de $1 \mathrm{~g}$ en $5 \mathrm{~mL}$ de solución salina estéril. Se tomaron dos alícuotas de $1.5 \mathrm{~mL}$, una se calentó $\left(60^{\circ} \mathrm{C} / 10 \mathrm{~min}\right)$ y ambas se inocularon en medio de carne picada e incubaron a $35^{\circ} \mathrm{C}$ por 7 días. A los 2 y 7 días se tomaron alícuotas de $0.1 \mathrm{~mL}$ que fueron inoculadas en la periferia de placas de agar sangre haciendo una línea de 3-4 cm y se incubaron a $35^{\circ} \mathrm{C}$ por 24 horas en anaerobiosis (GasPak) para permitir el desplazamiento tipo "swarming". Luego se tomaron muestras del borde de la película de "swarming", si estaba presente, y se inocularon en placas de agar sangre (4\% agar) para aislar colonias discretas. Las cepas similares a $C$. tetani fueron analizadas bioquímicamente y por ELISA para identificar la tetanospasmina.

Resultados. Diez (33\%) cepas de las 30 muestras fueron identificadas como $C$. tetani toxigénicos. Otras especies de clostridios que exhibieron una película de "swarming" similar fueron C. putrificum y $C$. glicolicum. Además se aislaron cepas de $C$. sporogenes, $C$. fallax, $C$. haemolyticum y $C$. beijerinkii.

Discusión. Estos resultados confirman la alta frecuencia de cepas toxigénicas de $C$. tetani en suelos costarricenses, como fue descrito previamente para suelos de la Universidad de Costa Rica, de los cuales se aisló un $43 \%$ de cepas de $C$. tetani, el $30 \%$ de las cuales fueron toxigénicas, una proporción similar a lo descrito en el presente

Solicitud de sobretiros: Dr. Francisco Hernández-Chavarría, Unidad de Microscopia Electrónica, Universidad de Costa Rica, San José, Costa Rica. E-mail: hchavarr@cariari.ucrac.cr 
F Hernández-Chavarría, F Cháves, M Umaña.

trabajo. Desde el punto de vista de la salud pública esta alta frecuencia de $C$. tetani en suelos es un recordatorio para mantener al día los esquemas de vacunación y la aplicación del toxoide tetánico a los pacientes con traumatismos para prevenir casos clínicos de tétanos. (Rev Biomed 2001; 12:80-84)

Palabras clave: Clostridium tetani, clostridios, muestras de suelo, fenómeno de "swarming".

\section{SUMMARY.}

Isolation Clostridium tetani in Puntarenas City, Costa Rica and the swarming phenomenon.

Objective. To determine the occurrence of Clostridium tetani in soil samples collected from the city of Puntarenas, Costa Rica, and to evaluate strain toxigenicity using a capture ELISA technique.

Material and methods. Thirty soil samples were collected and dried at $35^{\circ} \mathrm{C}$ for at least two weeks. Suspensions were obtained from each sample by placing $1 \mathrm{~g}$ in $5 \mathrm{~mL}$ of sterile saline solution. Two aliquots of $1.5 \mathrm{~mL}$ were taken from each sample, one of which was heated $\left(60^{\circ} \mathrm{C} / 10 \mathrm{~min}\right)$. Both were inoculated in chopped meat medium (CMM) and incubated at $35^{\circ} \mathrm{C}$ for 7 days. At days 2 and 7 aliquots of 0.1 $\mathrm{mL}$ from each CMM culture were streaked on the periphery of blood agar plates making a line of 2-3 cm and incubated anaerobically (GasPak) for $24 \mathrm{~h}$ to allow swarming displacement. Then a sample of the swarming film, if present, was collected and inoculated on hard blood agar plates (4\% agar) to isolate discrete colonies. Isolated strains resembling $C$. tetani were analyzed by their biochemical profile and ELISA in order to detect tetanospasmin.

Results. Ten (33\%) samples out of 30 were identified as toxigenic $C$. tetani. Other isolated species of clostridia which exhibited a similar swarming film were $C$. putrificum and $C$. glicolicum. C. sporogenes, C. fallax, C. haemolyticum, and C. beijerinkii were also isolated.

Discussion. These results confirm the high frequency of toxigenic $C$. tetani from Costa Rican soil samples, as was described in a previous study of soil samples from the University of Costa Rica, in which $43 \%$ of strains isolated were identified as C. tetani, and $30 \%$ of those were toxigenic, a similar proportion to that reported in the present paper. From the standpoint of public health policy, the high prevalence of this agent in soil is a reminder of the importance of strict adherence to vaccination schedules and the application of tetanus toxoid to any patient with a traumatic lesion, to prevent cases of clinical tetanus. (Rev Biomed 2001; 12:80-84)

Key words: Clostridium tetani, clostridia, soil samples, swarming phenomenon.

\section{INTRODUCCIÓN.}

El género Clostridium está integrado por más de 100 especies de bacilos anaerobios, esporulados, clasificados como Gram positivos, aunque los cultivos viejos de algunas especies se tiñen como Gram negativos (1). Por lo menos 20 especies son toxigénicas (2) y se asocian con diversos cuadros clínicos, como gangrena gaseosa, colitis pseudomembranosa, diarrea y las neuroparálisis botulínica (2-7) y tetánica (2). Esta última es producida por la tetanospasmina, que bloquea la liberación de inhibidores de la contracción en las placas motoras, llevando la contracción tetánica que caracteriza el cuadro de tétanos (8).

En términos generales, las especies del género Clostridium tienen una distribución mundial, y $C$. tetani, con el cuadro clínico de tétanos es un ejemplo de esa amplia distribución. Esta enfermedad ha sido controlada en muchas regiones, gracias a un sistema de vacunación efectivo, como se probó durante la Segunda Guerra Mundial (9); no obstante, sigue siendo importante en países en desarrollo, debido a falta de cobertura de esos esquemas de vacunación $(10,11)$. A pesar

\section{Revista Biomédica}




\section{Aislamiento de Clostridium tetani.}

de el tétanos presenta una prevalencia muy baja en los países con un buen esquema de inmunizaciones, la bacteria sigue presente en el suelo y ése es un concepto importante que debe estar vigente, pues al reducirse la presencia de la enfermedad o bien erradicarla en algunos territorios, se puede caer en el concepto equivocado de que la bacteria ha sido eliminada del ambiente, lo que puede repercutir en fallas en la aplicación del toxoide en pacientes con traumatismos.

Por otra parte, al menos 15 especies del género Clostridium presentan el fenómeno de "swarming" (12). Éste se describe como una propiedad de algunos bacilos, tanto Gram positivos como Gram negativos, según la cual, los bacilos cortos se transforman en gigantescas formas hiperflageladas que se desplazan sobre el medio de cultivo sólido, formando un velo tenue de crecimiento, que puede presentar algunos patrones característicos, como ocurre con C. oceanicum (13). C. tetani muestra un comportamiento similar, excepto que el velo de crecimiento es homogéneo y en sólo 24 horas cubre toda la superficie de una placa de agar sangre (placa de Petri de $90 \mathrm{~mm}$ de diámetro), siendo la especie del género que muestra el fenómeno de "swarming" más exacerbadamente (14). En 1984 Smith (15) indicó que el desplazamiento tipo "swarming" de C. tetani podría facilitar su aislamiento, lo cual se aplicó en un estudio realizado con suelos obtenidos del campus de la Ciudad Universitaria Rodrigo Facio, de la Universidad de Costa Rica, encontrándose una prevalencia de C. tetani del $43 \%$ (16). No obstante, posteriormente se publicó una nota que resaltaba la baja frecuencia de $C$. tetani en Costa Rica, indicando que su frecuencia era de sólo el $10 \%$ (17), lo que correspondía a la identificación de la bacteria o su efecto toxigénico en 3 de 30 muestras de suelo. Tal incongruencia entre ambos informes podría deberse a diferencias en la metodología empleada. Por eso en este estudio, se buscó la bacteria en suelos de la ciudad de Puntarenas, Costa Rica, utilizando el fenómeno de "swarming" de esta especie como criterio selectivo para promover su aislamiento, tal como se había descrito previamente (16).

\section{MATERIAL Y MÉTODOS.}

Se colectaron muestras de suelo $(c a .30 \mathrm{~g})$ a uno $15 \mathrm{~cm}$ de profundidad, en 30 diferentes sitios de la ciudad de Puntarenas (costa pacífica de Costa Rica, Latitud 10.0 norte y longitud 80.50 oeste).

Las muestras se desecaron a $30^{\circ} \mathrm{C}$ al menos durante 2 semanas, se molieron en morteros, se tamizaron a través de mallas con una porosidad de ca. $0.5 \mathrm{~mm}$ de diámetro y de cada muestra se hizo una suspensión de $1 \mathrm{~g}$ en $5 \mathrm{~mL}$ de solución salina estéril. De esa suspensión se tomaron dos alícuotas de $1.5 \mathrm{~mL}$ cada una. Una se calentó a $60^{\circ} \mathrm{C} / 10 \mathrm{~min}$. y ambas se inocularon en sendos tubos de caldo de carne cocida prereducidos. Todos los tubos se incubaron a $35^{\circ} \mathrm{C}$ durante 2 y 7 días. De cada tubo se tomó una alícuota de $0.1 \mathrm{~mL}$ perforando el tapón del tubo con una aguja hipodérmica y extrayendo la muestra con una jeringa de tuberculina, de manera que no se perdiera la atmósfera anaerobia del tubo. Las muestras se depositaron en la periferia de una placa de agar sangre y se distribuyeron a lo largo de una estría de unos 3 a $4 \mathrm{~cm}$ cercana al borde de la placa. Las placas se incubaron a $35^{\circ} \mathrm{C}$ por 24 horas en jarras de anaerobiosis con sobre generador de $\mathrm{C}_{2}$ y $\mathrm{N}_{2}$ (GasPak). Si hubo crecimiento en forma de película, tipo "swarming" que se alejara del sitio de inoculación se tomó una asada del extremo distal de esa película y se rayó en placas de agar sangre con $4 \%$ de agar, para evitar el desplazamiento tipo "swarming" y obtener colonias discretas para verificar la pureza de las cepas aisladas. Las cepas aisladas se identificaron mediante pruebas bioquímicas y cromatográficas y aquellas identificadas como $C$. tetani y que presentaron una película de crecimiento tipo "swarming" similar al de esta especie se sometieron a una prueba de ELISA de captura para identificar la tetanospasmina. La prueba de ELISA utilizada se realizó en placas de microtítulo recubiertas con suero anti tetanospasmina (Berna) y a cada pocillo 


\section{F Hernández-Chavarría, F Cháves, M Umaña.}

se agregó el extractos libres de células de las cepas sospechosas; como segundo anticuerpo se adicionó un anticuerpo de conejo contra el fragmento $\mathrm{C}$ y la reacción se evidenció con un conjugado de $\operatorname{IgG}$ de cabra anti IgG de conejo marcada con peroxidasa; se leyó a 490 nM y se tomó como positivo una lectura de DO de 0.149 ó mayor (17).

\section{RESULTADOS.}

A partir de 30 muestras de suelo se aislaron 10 cepas de $C$. tetani cuya capacidad toxigénica se evidenció por la prueba de ELISA. Esto corresponde a una frecuencia de aislamiento de $33 \%$.

Otras especies aisladas frecuentemente fueron C. sporogenes, C. fallax, C. putrificum, $C$. glicolicum, $C$. haemolyticum y $C$. beijerinkii; sin embargo, sus películas de desplazamiento son notablemente diferentes, caracterizadas ya sea por colonias en cabeza de medusa como ocurre en $C$. sporogenes o en $C$. beijerinkii o bien por una película de crecimiento diferente a la exhibida por C. tetani. No obstante, $C$. putrificum y $C$. glicolicum muestran una película de crecimiento similar a la de C. tetani.

\section{DISCUSIÓN.}

En un estudio previo realizado en 30 muestras de suelo de la Universidad de Costa Rica Costa Rica se aislaron 13 cepas de C. tetani (43\%). De esas cepas 9 eran toxigénicas, lo que equivale a una frecuencia del $30 \%$ de aislamiento de cepas toxigénicas (16). En el presente trabajo sólo se identificaron las cepas toxigénicas, ya que las cepas sospechosas tanto por su perfil bioquímico, como por la morfología del fenómeno de "swarming" se sometieron a la prueba de ELISA, lo que permitió identificar una frecuencia de aislamiento del 33\%. Previamente la prueba de ELISA utilizada había sido evaluada contra la prueba biológica, encontrándose que correlacionaban los datos positivos de ambos, o sea una lectura de ELISA de una DO de 0.149 ó más y la muerte de los ratones inoculados con el extracto de $C$. tetani (18). La reducción de los casos de tétano en la era posvacunación con el toxoide tetánico es notable; por ejemplo en Estados Unidos de Norte América se estimó que en 1948 se presentaron 1560 casos y en 1997 se detectaron sólo 43, lo que implica una reducción de $-97.24 \%$ (19). También Costa Rica ha experimentado una reducción notable, pues antes de 1970 anualmente se presentaban entre 200 y 300 muertes por tétano y en la década de 1990 los casos en algunos años no se han presentado $u$ ocurren menos de 5 casos por año (20). Sin embargo, es importante tener presente que el agente etiológico es un habitante normal de suelos y que la vacunación no lo elimina ni reduce su circulación, como ocurre con otras enfermedades prevenibles por vacunación, como el sarampión y la rubéola. Por lo tanto, en el caso del tétanos una buena cobertura de los esquemas de vacunación es la única medida preventiva efectiva y la aplicación del toxoide tetánico debe mantenerse vigente en pacientes con traumatismos.

Las razones anteriores, estimulan la importancia determinar la prevalencia de $C$. tetani en suelos lo más acertadamente posible, pues ante la reducción de casos clínicos y el informe de baja frecuencia de la bacteria en el suelo, se puede caer en el espejismo de una eliminación de la bacteria, lo que puede menoscabar la manutención del esquema de vacunación y descuidar la aplicación del toxoide en pacientes traumatizados.

\section{AGRADECIMIENTO.}

Se agradece el apoyo y ayuda técnica de Pablo Vargas y la discusión y revisión del manuscrito realizada por el Dr. Jorge Danilo García, UCR. También se agradece el apoyo de la Vicerrectoría de Investigación de la Universidad de Costa Rica (Proyecto 430-96-215).

\section{REFERENCIAS.}

1.- Cato EP, George WL, Finegold SM. Genus Clostridium Prazmowski 1880. En: Sneath PHA, Mair NS, Sharpe ME, Holt JG, editores. Bergey's Manual of Systematic

\section{Revista Biomédica}




\section{Aislamiento de Clostridium tetani.}

Bacteriology, vol 2. Baltimore: Williams and Wilkins; 1986. p. 1146-200.

2.- Hatheway CL. Toxigenic clostridia. Clin Microbiol Rev 1990; 3:66-98.

3.- Shapiro RL, Hatheway C, Swerdlow DL. Botulim in the United States: A clinical and epidemiologic review. Ann Intern Med 1998; 129: 221-8.

4.- Hall JD, McCroskey LM, Pincomb BJ, Hatheway CL. Isolation of an organism resembling Clostridium baratii which produces type $\mathrm{F}$ botulinal toxin from an infant with botulism. J Clin Microbiol 1985; 21: 654-5.

5.- McCroskey LM, Hatheway CL. Woodruff BA, Greenberg JA, Jurgenson P. Type F botulism due to neurotoxigenic Clostridium baratii from an unknown source in an adult. J Clin Microbiol 1991; 29:2618-20.

6.- Aureli P, Fenicia L, Pasolini B, Gianfranceschi M, McCroskey LM, Hatheway CL. Two cases of type E infant botulinum caused by neurotoxigenic Clostridium butyricum in Italy. J Infect Dis 1986; 154: 207-11.

7.- Poulain B, Molgo J. Botulinal neurotoxin: mode of action on neurotransmitter release. Meth Neurosc 1992; 8:38-54.

8.- Mochida S, Poulain B, Weller U, Habermann E, Tauc L. Light chain of tetanus toxin intracellularly inhibits acetylcoline release at neuro-neuronal synapses, and its internalization is mediated by heavy chain. FEBS 1989; 253:47-51.

9.- Axnick NW, Alexander ER. Tetanus in the United States: A review of the problem. Amer J Publ Hlth 1957; 47:1493-1501.

10.- Whitman C, Belgharbi L, Gasse F, Torel C, Mattei V, Zoffmann H. Progress towards the global elimination of neonatal tetanus. World Hlth Stat Q 1992; 45: 248-56.

11.- Shann F, Steinhoff MC. Vaccines for children in rich and poor countries. Lancet 1999; 354 (Supl II):7-11.

12.- Hernández F, Rodríguez E, Umaña M, Vargas P. Isolation of swarmer clostridia from soil samples. Rev Biol Trop 1997; 45:1243-5.

13.- Ariza R, Hernández F. Análisis ultraestructural del fenómeno de "swarming" en Clostridium oceanicum y $C$. beijerinckii. Rev Cost Cienc Méd 1999; 20:29-34.
14.- Hernández F, Rodríguez E. The swarming phenomenon of Clostridium tetani. Rev Biol Trop 1992; 41:857-9.

15.- Smith LDS, Williams BL. The pathogenic anaerobic bacteria. $3^{\text {rd }}$ ed. Illinois: Thomas Publisher; 1984. p. 13747.

16.- Hernández F, Rodríguez E, Vargas P, Umaña M. Clostridium tetani en suelos de la Ciudad Universitaria Rodrigo Facio. Rev Cost Cienc Med 1996; 17:34-8.

17.- Rodríguez E, Gamboa MM. Baja prevalencia de Clostridium tetani en suelos de la Meseta Central de Costa Rica. Rev Biomed 1997; 8:234-6.

18.- Cháves F, León G, Alape F, Hernández-Chavarría F. Detección inmunoenzimática de la toxina de Clostridium tetani: Una alternativa a las pruebas biológicas con ratones. Rev Biol Trop. En prensa.

19.- Chen RT, DeStefano F. Vaccine adverse events: causal or coincidental? Lancet 1998; 351:611-2.

20.- Anderson RM, May RM. Directly transmitted infectious diseases: control by vaccination. Science 1982; 215:1053-60. 